\title{
Re: There is no association between combined oral hormonal contraceptives and depression: a Swedish register-based cohort study
}

\author{
Jack Lowe-Zinola ${ }^{1}$, Oguljemal Redjepova ${ }^{2}$, and Christopher Griffin ${ }^{3}$ \\ ${ }^{1}$ University Hospitals Birmingham NHS Foundation Trust \\ ${ }^{2}$ Sandwell and West Birmingham Hospitals NHS Trust \\ ${ }^{3}$ Notre Dame Medical School
}

January 28, 2022

Re: There is no association between combined oral hormonal contraceptives and depression: a Swedish register-based cohort study

Jack Lowe-Zinola ${ }^{\mathrm{a}}$, Oguljemal Redjepova ${ }^{\mathrm{b}}$, Christopher Griffin ${ }^{\mathrm{c}}$

${ }^{a}$ Good Hope Hospital, University Hospitals Birmingham NHS Trust, Rectory Road, Sutton Coldfield, United Kingdom

${ }^{b}$ City Hospital Birmingham, Sandwell and West Birmingham Hospitals NHS Trust, Dudley Road, Birmingham, United Kingdom

${ }^{c}$ Department of Obstetrics and Gynaecology, Notre Dame Medical School, Fremantle, Western Australia 6160

Corresponding author:

Jack Lowe-Zinola

Email: jack.lowe-zinola@nhs.net

Professional address: Good Hope Hospital, Rectory Road, Sutton Coldfield B75 7RR

Telephone: 01214242000

Dear Sirs,

We found the recent article from Lundin and colleagues produced a most diverse and engaging discussion based within the present day pandemic of mental health issues.

Notably, this Swedish population based study is at odds with its Nordic neighbour Denmark where the opposite effect of oral hormonal contraceptives upon depression was found [1]. As intimated by the authors, the confounders are endless, but what sprung to our minds was the difference in dietary habits between the two Nordic countries.

A retrospective analysis of Swedish and Danish dietary habits, using data from Food Balance Sheets over a period of 23 years, demonstrated a greater consumption of meats and fat, and a lower consumption of fish, fruit and berries, in Denmark as compared to Sweden. Additionally, the authors found that, whilst disparities in dietary habits exist in both countries, there was a propensity toward wider social difference in Denmark [2]. 
It has been demonstrated that the gut microbiome plays an important role in disease modulation, and diet is understood to have a significant influence on the microbiome composition [3]. The use of the same hormonal contraceptives as in the Swedish study, have been shown to produce a positive anti-inflammatory shift in the vaginal microbiome of users [4]. There is, however, a potential reduction in the gut microbiome diversity amongst some users of hormonal contraception (HC) [5]. This reduced diversity is known to be associated with decreased well-being scores and increased anxiety [6]. The action of the HC upon the gut microbiome may explain an apparent clinical psychiatric heterogeneity amongst the two aforementioned studies.

Therefore, might we consider diet as a particular, modifiable, contributory confounder for the findings of the study? If so, should we be counselling our patients to examine their dietary habits to avoid any potentially negative impact of the hormonal contraception upon their wellbeing?

We would be most interested to hear the view of the authors but congratulate the group upon their work and perseverance to publish.

Disclosure of interest

The authors declare that they have no conflict of interest

References

[1] Hyland P, Shevlin M, Elklit A, et al. Social, familial and psychological risk factors for mood and anxiety disorders in childhood and early adulthood: a birth cohort study using the Danish Registry System. Social Psychiatry and Psychiatric Epidemiology 2016; 51(3): 331-8. doi: 10.1007/s00127-016-1171-1

[2] Groth MV, Fagt S. Udviklingen i kostvaner i Danmark og Sverige siden 1960'erne [Trends in dietary habits in Denmark and Sweden since the 1960s]. Ugeskr Laeger 2001;163(4): 425-9. Danish. PMID: 11218777

[3] Singh R, Chang H, Yan D, et al. Influence of diet on the gut and microbiome and implications for human health. Journal of Translational Medicine 2017; 15(1): 73. doi 10.1186/s12967-017-1175-y

[4] Brooks J, Edwards D, Blithe D, et al. Effects of combined oral contraceptives, depot medroxyprogesterone acetate and the levonorgestrel-releasing intrauterine system on the vaginal microbiome.Contraception 2017; 94(4): 405-13. doi: 10.1016/j.contraception.2016.11.006

[5] Mihajlovic J, Leutner M, Hausmann B, et al. Combined hormonal contraceptives are associated with minor changes in composition and diversity in gut microbiota of healthy women. Environmental Microbiology 2021; 23(6): 3037-47. doi: 10.1111/1462-2920.15517

[6] Hayes C, Peters B, Foster J. Microbes and mental health: Can the microbiome help explain clinical heterogeneity in psychiatry? Frontiers in Neuroendocrinology 2020; 58: 100849. doi: 10.1016/j.yfrne.2020.100849 